\title{
Job Stress and Neuropeptide Response Contributing to Food Intake Regulation
}

\author{
Ki-Woong Kim ${ }^{1}$, Yong Lim Won ${ }^{1}$, Kyung Sun Ko ${ }^{1}$ and Seong-Kyu Kang ${ }^{2}$ \\ ${ }^{1}$ Occupational Safety and Health Research Institute, KOSHA, Ulsan, Korea \\ ${ }^{2}$ Korean Occupational Safety and Health Agency, Ulsan, Korea
}

(Received October 15, 2015; Revised December 3, 2015; Accepted December 30, 2015)

\begin{abstract}
The purpose of the present study is to investigate the correlations between food intake behavior and job stress level and neuropeptide hormone concentrations. Job strain and food intake behavior were first identified using a self-reported questionnaire, concentrations of neuropeptide hormones (adiponectin, brain derived neurotrophic factor [BDNF], leptin, and ghrelin) were determined, and the correlations were analyzed. In the results, job strain showed significant correlations with adiponectin (odds ratio [OR], 1.220; 95\% confidence interval [CI], 1.001 1.498; $p<0.05$ ) and BDNF (OR, 0.793; 95\% CI, 0.646 0.974; $p<$ 0.05 ), and ghrelin exhibited a significant correlation with food intake score (OR, 0.911; 95\% CI, 0.842 $0.985, p<0.05$ ). These results suggest that job stress affects food intake regulation by altering the physiological concentrations of neuropeptide hormones as well as emotional status.
\end{abstract}

Key words: Job stress, Food intake behavior, Neuropeptides, Workers

\section{INTRODUCTION}

According to a World Health Organization (WHO) report, more than 3.5 million people suffer from depression worldwide, and $7 \sim 12 \%$ of adults need medical intervention due to mental disorders such as depression or anxiety (1). These findings seem to be due to members of society being required to change and adapt mentally and physically along the rapid changes in overall environments including society, politics, economy, and culture as well as industrial structure due to scientific and technological developments. Processes of change and adaptation require time that varies widely among individuals and causes various problems. One of the representative problems is mental health issues such as stress and depression caused by gaps between physical and mental adaptations depending on social needs. In particular, since the knowledge-based economy and service industry have

Correspondence to: Ki-Woong Kim, Occupational Health Research Department, Occupational Safety and Health Research Institute, KOSHA, 400, Jongga-ro, Jung-gu, Ulsan 681-230, Korea.

E-mail: k0810@kosha.net

Seong-Kyu Kang

E-mail: skk@kosha.or.kr

This is an Open-Access article distributed under the terms of the Creative Commons Attribution Non-Commercial License (http:// creativecommons.org/licenses/by-nc/3.0) which permits unrestricted non-commercial use, distribution, and reproduction in any medium, provided the original work is properly cited. expanded, sedentary activities and interpersonal relationships are considered more important than dynamic activities, which could cause excessive stress, leading to a higher potential of mental disorders. Continuous excessive stresses cause mental diseases such as depression, anger, and aggressive behavior by seriously affecting emotional response regulation (2). Rapid emotional changes induce negative life habits, leading to changes in food intake habits $(3,4)$, which causes homeostasis regulation imbalances that induce metabolic diseases such as obesity, metabolic syndrome (MetS), and cardiovascular disease (CVD) (5). Despite the fact that the pathogenesis of obesity and MetS has not yet been completely revealed, the most plausible hypothesis is the occurrence by energy imbalances caused by the loss of neuronutritional control function (6). Since all of the body's organs are connected through its bionetwork, excessive stress increases the physiological level of cortisol and affects the emotional response (7), which changes food intake habits [4]. Emotional responses to stress vary among individuals but can manifest as rejection of dietary intake, overeating, and binge eating (8), which causes energy imbalances and leads to diseases including malnutrition, obesity, and MetS $(9-12)$. The body responds to stress by interacting with the hypothalamic-pituitary-adrenal (HPA) axis and responds to excessive stress by elevating cortisol and glucocorticoid hormone secretions, which affects energy balance regulation (13). It has also been reported that food intake habits are closely related with physiological concentrations of neu- 
ropeptides, such as adiponectin, brain derived neurotrophic factor (BDNF), leptin, and ghrelin, that are involved in the regulation of food intake as well as the HPA axis $(11,12)$. Therefore, some researchers have studied the correlation between stress-induced food intake behavior and neuropeptide concentrations (13-16). However, their results varied. In addition, most study subjects were collected from the general population and had severe stress in the past or mental diseases such as depression (patient-control group study), and animals that were exposed to enough stress to show stress responses, with whom the studies found positive results. Currently, although studies on job stress and worker health have been conducted, most were survey studies using questionnaires, whereas studies on the mechanism of correlation between stress and food intake behavior are lacking.

Therefore, this study aimed to analyze the correlation between job stress level and food intake behavior of male manufacturing workers and investigate the effect of physiological neuropeptide concentration on food intake behavior.

\section{MATERIALS AND METHODS}

Study subjects. Study subjects were first given detailed explanations about the study purpose, methods, and privacy protection method, and then a survey was performed of the 365 workers who volunteered. Of them, data from 35 workers whose questionnaires were incompletely answered were excluded; as such, the job stress levels of 330 workers were ultimately evaluated. This study was approved by the internal review board of the Occupational Safety \& Health Research Institute in Korea.

General and job characteristics. General characteristics such as age, smoking and drinking habit, lifestyle, and job characteristics were obtained from self-reported questionnaire and interview.

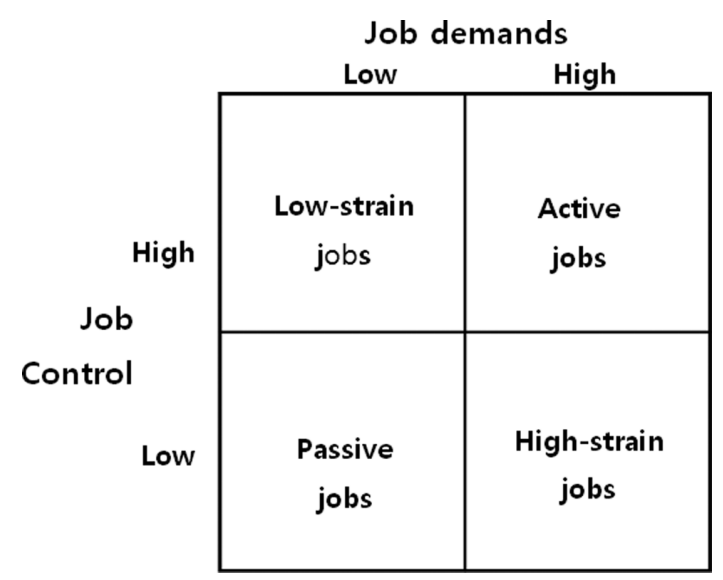

Fig. 1. The job demands-control model.
Levels of job strain. The Job Content Questionnaire (JCQ) developed by Karasek was used to measure job stress (17). The JCQ is composed of psychological job demand (item 5), decision latitude (item 9), supervisor support (item 4), and co-worker support (item 4). Each item is ranked on a 4-point scale, namely, strongly disagree to strongly agree (strongly disagree, disagree, agree and strongly agree). Job strain level was calculated by dividing the job demands score by the job control score (Fig. 1). That is, high strain jobs are representative of jobs where demands are high and control is low and low strain jobs are low in demands and high in control.

Food intake behavior. Food intake behavior was assessed by the modified to the method of Son and Kim (18).

Questionnaire of food intake behavior is composed of intake amount and numbers ( 2 items), considering nutrition (1 item), salt intake (1 item) and favorite food (6 items). Each item is ranked on a 3-point scale, namely, almost never eat, some time, every day. A low score of food intake behavior means bad food intake behavior.

Measurement of anthropometric parameters and serum biochemistry test. Body mass index (BMI) and body fat $\%$ were measured with a body composition analyzer (X-SCAN plus II, Jawon Medical, Korea). Systolic and diastolic blood pressure was measured with the mercury manometer after a 10-minute rest. Subcutaneous fat thickness (SFT) and visceral fat thickness (VFT) were measured with ultrasonic diagnostic equipment (SonoAce 8800 , Medison Co., Korea), using a B mode ultrasound 3.5 MHz oval probe. Serum biochemistry tests for fasting glucose, triglyceride, total cholesterol, and HDL- and LDL-cholesterol were conducted with an automatic biochemistry analyzer (COBAS integra 400, Roche Diagnostics Ltd., Rotkreuz, Switzerland).

Measurement of cortisol and neuropeptides levels. Cortisol was measured with an automatic chemiluminescence immune analyzer (Sanofi Diagnostics Pasteur, Inc., Minnesota, USA). The sandwich ELISA kit (LINCO Research Inc., Missouri, USA) was used to measure leptin and total ghrelin in serum and plasma. Adiponectin and BDNF were measured with the sandwich ELISA kit (R\&D systems, Minnesota, USA), using the method proposed by the manufacturer.

Statistical analysis. Statistical analysis for all data was performed using SPSS software (version 18.0, SPSS Inc., Chicago, IL, USA). Analysis of variance (ANOVA) was used for comparisons among individual strain group. For correlation analysis between neuropeptides, job strain and food intake behavior, multiple logistic regression analysis was performed with neuropeptides as dependent variables 
and job strain, cortisol and food intake behavior as independent variables. All the data are expressed as mean and standard deviation.

\section{RESULTS}

Total subjects and group characteristics. The subjects' general characteristics are presented in Table 1 by job strain level (high, low, active, and passive). The mean age (40.3 years) and the mean employment period (149.1 months) were significantly higher in the low strain group $(p=0.001)$, whereas there were no differences in alcohol drinking, exercise, sleeping hours, TV watching time, and food intake habits. Despite the lack of statistical significance, the high strain group had a higher proportion of smokers (64.9\%) (p $=0.096$ ). The anthropometric parameter and serum biochemistry results of the study subjects are presented in Table 2 . The mean body mass index and body fat $\%$ of the total subjects were $23.4 \pm 2.9 \mathrm{~kg} / \mathrm{m}^{2}$ and $20.5 \%$, respectively, and waist circumference, triceps skin-fold thickness, and visceral fat thickness were $83.2 \pm 8.1 \mathrm{~cm}, 1.58 \pm 0.56$ $\mathrm{cm}$, and $4.11 \pm 1.40 \mathrm{~cm}$, respectively. Systolic blood pressure and diastolic blood pressure were 127.1 \pm 14.4 and $75.1 \pm 10.1 \mathrm{mmHg}$, respectively. Although there was no significant difference in the measurement values of these parameters among job strain groups, the mean systolic blood pressure of the active strain group was higher than those of other job strain groups $(p=0.063)$. Mean concentrations of total cholesterol, high-density lipoprotein (HDL) cholesterol, and low-density lipoprotein cholesterol of the total subjects were $189.8 \pm 34.4 \mathrm{mg} / \mathrm{dL}, 50.5 \pm 11.9 \mathrm{mg} / \mathrm{dL}$, and $111.1 \pm 30.8 \mathrm{mg} / \mathrm{dL}$, respectively, while the triglyceride and fasting glucose concentrations were $176.4 \pm 148.6$ and $90.6 \pm 14.9 \mathrm{mg} / \mathrm{dL}$, respectively. Of these serum biochemistry results, the low strain group had a significantly lower mean HDL cholesterol value $(46.4 \pm 10.5 \mathrm{mg} / \mathrm{dL})$ than the other job strain groups $(F=4.500, p=0.004)$, whereas the mean fasting glucose concentration was significantly lower $(\mathrm{F}=3.529, \mathrm{p}=0.015)$ in the high strain group $(86.3 \pm 10.5 \mathrm{mg} / \mathrm{dL})$ (Table 2$)$.

Table 1. General characteristics

\begin{tabular}{lcccccc}
\hline \hline Variables & $\begin{array}{c}\text { Total } \\
(\mathrm{n}=330)\end{array}$ & $\begin{array}{c}\text { High strain } \\
(\mathrm{n}=77)\end{array}$ & $\begin{array}{c}\text { Low strain } \\
(\mathrm{n}=70)\end{array}$ & $\begin{array}{c}\text { Active strain } \\
(\mathrm{n}=101)\end{array}$ & $\begin{array}{c}\text { Passive strain } \\
(\mathrm{n}=82)\end{array}$ & Statistics, $\mathrm{p}$-value \\
\hline Age, years & $38.0 \pm 8.9$ & $34.8 \pm 7.8$ & $40.3 \pm 7.7$ & $39.2 \pm 9.1$ & $37.8 \pm 9.6$ & $\mathrm{~F}=5.796, \mathrm{p}=0.001$ \\
Working duration, month & $115.9 \pm 88.9$ & $86.7 \pm 84.3$ & $149.1 \pm 85.8$ & $130.8 \pm 91.5$ & $96.5 \pm 80.3$ & $\mathrm{~F}=8.841, \mathrm{p}=0.001$ \\
Working hours (per day) & $9.4 \pm 1.7$ & $9.4 \pm 1.5$ & $9.6 \pm 1.7$ & $9.4 \pm 2.0$ & $9.2 \pm 1.4$ & $\mathrm{~F}=0.554, \mathrm{p}=0.645$ \\
Smokers, n (\%) & $176(53.3 \%)$ & $50(64.9 \%)$ & $37(52.9 \%)$ & $44(43.6 \%)$ & $45(54.9 \%)$ & $\mathrm{F}=2.129, \mathrm{p}=0.096$ \\
Cigarettes per day & $9.3 \pm 8.2$ & $10.3 \pm 7.8$ & $10.0 \pm 8.7$ & $8.3 \pm 8.4$ & $9.1 \pm 7.8$ & $\mathrm{~F}=1.108, \mathrm{p}=0.346$ \\
Drinkers, n (\%) & $277(83.9 \%)$ & $63(81.8 \%)$ & $62(88.6 \%)$ & $81(81.0 \%)$ & $71(86.6 \%)$ & $\mathrm{F}=1.062, \mathrm{p}=0.365$ \\
Alcohol consumption (g/week) & $80.5 \pm 57.2$ & $82.5 \pm 58.7$ & $87.7 \pm 51.8$ & $79.4 \pm 66.3$ & $73.8 \pm 47.3$ & $\mathrm{~F}=0.758, \mathrm{p}=0.518$ \\
Regular exercise, (\%) & $172(52.1 \%)$ & $38(49.4 \%)$ & $38(54.3 \%)$ & $60(59.4 \%)$ & $36(43.9 \%)$ & $\mathrm{F}=1.478, \mathrm{p}=0.221$ \\
Time watching TV (per day) & $1.6 \pm 0.9$ & $1.8 \pm 0.9$ & $1.4 \pm 0.9$ & $1.6 \pm 0.9$ & $1.6 \pm 0.9$ & $\mathrm{~F}=1.557, \mathrm{p}=0.200$ \\
Sleeping hours (per day) & $6.6 \pm 1.5$ & $6.6 \pm 1.0$ & $6.6 \pm 0.9$ & $6.8 \pm 2.2$ & $6.6 \pm 0.9$ & $\mathrm{~F}=0.881, \mathrm{p}=0.451$ \\
Food intake score & $20.6 \pm 2.8$ & $19.8 \pm 5.7$ & $20.9 \pm 3.1$ & $20.7 \pm 2.5$ & $20.3 \pm 5.7$ & $\mathrm{~F}=0.672, \mathrm{p}=0.570$ \\
\hline
\end{tabular}

Table 2. Levels of anthropometric parameters and serum biochemistry by job strain groups

\begin{tabular}{lcccccc}
\hline \hline Variables & $\begin{array}{c}\text { Total } \\
(\mathrm{n}=330)\end{array}$ & $\begin{array}{c}\text { High strain } \\
(\mathrm{n}=77)\end{array}$ & $\begin{array}{c}\text { Low strain } \\
(\mathrm{n}=70)\end{array}$ & $\begin{array}{c}\text { Active strain } \\
(\mathrm{n}=101)\end{array}$ & $\begin{array}{c}\text { Passive strain } \\
(\mathrm{n}=82)\end{array}$ & Statistics, $\mathrm{p}$-value \\
\hline Anthropometric parameters & & & & & & \\
$\quad$ Body mass index, kg/m ${ }^{2}$ & $23.4 \pm 2.9$ & $23.1 \pm 3.2$ & $23.8 \pm 3.0$ & $23.4 \pm 2.9$ & $23.3 \pm 2.6$ & $\mathrm{~F}=0.781, \mathrm{p}=0.505$ \\
$\quad$ Body fat \% & $20.5 \pm 5.6$ & $19.8 \pm 5.7$ & $21.4 \pm 5.2$ & $20.6 \pm 5.7$ & $20.3 \pm 5.7$ & $\mathrm{~F}=1.008, \mathrm{p}=0.390$ \\
Waist circumference, cm & $83.2 \pm 8.1$ & $82.4 \pm 8.0$ & $85.1 \pm 7.8$ & $83.4 \pm 8.3$ & $82.1 \pm 7.8$ & $\mathrm{~F}=2.067, \mathrm{p}=0.104$ \\
Subcutaneous fat thickness, cm & $1.58 \pm 0.56$ & $1.58 \pm 0.65$ & $1.64 \pm 0.53$ & $1.53 \pm 0.51$ & $1.57 \pm 0.55$ & $\mathrm{~F}=0.564, \mathrm{p}=0.639$ \\
Visceral fat thickness, cm & $4.11 \pm 1.40$ & $3.88 \pm 1.34$ & $4.22 \pm 1.39$ & $4.29 \pm 1.50$ & $4.01 \pm 1.34$ & $\mathrm{~F}=1.546, \mathrm{p}=0.203$ \\
Systolic blood pressure, mmHg & $127.1 \pm 14.4$ & $125.8 \pm 13.3$ & $127.1 \pm 12.9$ & $128.7 \pm 15.8$ & $126.4 \pm 14.8$ & $\mathrm{~F}=0.674, \mathrm{p}=0.568$ \\
Diastolic blood pressure, mmHg & $75.1 \pm 10.1$ & $73.2 \pm 10.4$ & $74.9 \pm 9.1$ & $77.2 \pm 10.1$ & $74.5 \pm 10.5$ & $\mathrm{~F}=2.461, \mathrm{p}=0.063$ \\
\hline Serum biochemistry & & & & & & \\
$\quad$ Total cholesterol, mg/dL & $189.8 \pm 34.4$ & $186.3 \pm 35.7$ & $191.0 \pm 32.4$ & $189.1 \pm 35.0$ & $193.1 \pm 34.4$ & $\mathrm{~F}=0.556, \mathrm{p}=0.644$ \\
HDL-cholesterol, mg/dL & $50.5 \pm 11.9$ & $52.9 \pm 11.6$ & $46.4 \pm 10.5$ & $50.0 \pm 11.9$ & $52.1 \pm 12.5$ & $\mathrm{~F}=4.500, \mathrm{p}=0.004$ \\
LDL-cholesterol, mg/dL & $111.1 \pm 30.8$ & $107.3 \pm 31.9$ & $115.0 \pm 33.0$ & $108.8 \pm 26.2$ & $114.2 \pm 32.9$ & $\mathrm{~F}=1.231, \mathrm{p}=0.299$ \\
Triglyceride, mg/dL & $176.4 \pm 148.6$ & $164.3 \pm 138.2$ & $181.1 \pm 136.6$ & $190.2 \pm 164.1$ & $166.7 \pm 148.9$ & $\mathrm{~F}=0.598, \mathrm{p}=0.617$ \\
Fasting glucose, mg/dL & $90.6 \pm 14.9$ & $86.3 \pm 10.5$ & $92.8 \pm 17.4$ & $92.9 \pm 15.3$ & $89.9 \pm 15.1$ & $\mathrm{~F}=3.529, \mathrm{p}=0.015$ \\
\hline
\end{tabular}


Table 3. Levels of hormones by job strain groups

\begin{tabular}{lcccccc}
\hline \hline Variables & $\begin{array}{c}\text { Total } \\
(\mathrm{n}=330)\end{array}$ & $\begin{array}{c}\text { High strain } \\
(\mathrm{n}=77)\end{array}$ & $\begin{array}{c}\text { Low strain } \\
(\mathrm{n}=70)\end{array}$ & $\begin{array}{c}\text { Active strain } \\
(\mathrm{n}=101)\end{array}$ & $\begin{array}{c}\text { Passive } \\
\text { strain } \\
(\mathrm{n}=82)\end{array}$ & Statistics, $\mathrm{p}$-value \\
\hline Cortisol, $\mathrm{nmol} / \mathrm{L}$ & $287.7 \pm 93.1$ & $279.3 \pm 97.5$ & $280.7 \pm 90.5$ & $289.8 \pm 92.4$ & $299.0 \pm 92.2$ & $\mathrm{~F}=0.761, \mathrm{p}=0.517$ \\
Adiponectin, $\mathrm{ng} / \mathrm{mL}$ & $3.63 \pm 3.31$ & $3.77 \pm 3.31$ & $2.87 \pm 3.32$ & $3.78 \pm 3.43$ & $3.97 \pm 3.11$ & $\mathrm{~F}=1.650, \mathrm{p}=0.178$ \\
BDNF, $\mathrm{pg} / \mathrm{mL}$ & $21.1 \pm 7.3$ & $19.5 \pm 6.6$ & $21.0 \pm 7.4$ & $21.3 \pm 7.9$ & $22.5 \pm 7.0$ & $\mathrm{~F}=2.171, \mathrm{p}=0.091$ \\
Leptin, $\mathrm{ng} / \mathrm{mL}$ & $4.87 \pm 3.67$ & $5.16 \pm 4.71$ & $4.76 \pm 2.61$ & $4.51 \pm 3.48$ & $5.17 \pm 3.58$ & $\mathrm{~F}=0.544, \mathrm{p}=0.652$ \\
Total ghrelin, $\mathrm{pg} / \mathrm{mL}$ & $12.7 \pm 2.6$ & $13.0 \pm 2.6$ & $12.6 \pm 2.4$ & $12.4 \pm 2.3$ & $12.7 \pm 3.2$ & $\mathrm{~F}=0.763, \mathrm{p}=0.515$ \\
\hline
\end{tabular}

Table 4. Interrelationship adjusted age, smoking and drinking habit between job strain and neuropeptides hormones using multiple logistic regression analysis

\begin{tabular}{lcccc}
\hline \hline $\begin{array}{l}\text { Independent } \\
\text { variables }\end{array}$ & $\begin{array}{c}\text { Adiponectin } \\
\text { Odds }(\beta \text {-value, 95\% C.I })\end{array}$ & \multicolumn{1}{c}{ Odds $(\beta$-value, 95\% C.I $)$} & $\begin{array}{c}\text { Leptin } \\
\text { Odds }(\beta \text {-value, 95\% C.I) }\end{array}$ & $\begin{array}{c}\text { Ghrelin } \\
\text { Odds }(\beta \text {-value, 95\% C.I) }\end{array}$ \\
\hline Job strain & $1.220(0.199,1.002-1.498) *$ & $0.793(-0.232,0.646-0.974) *$ & $0.839(-0.175,0.666-1.057)$ & $1.023(0.023,0.834-1.256)$ \\
Cortisol & $1.001(0.001,0.999-1.004)$ & $1.001(0.001,0.999-1.004)$ & $0.999(-0.001,0.996-1.002)$ & $1.000(0.000,0.997-1.002)$ \\
Food intake score & $0.974(-0.027,0.901-1.052$ & $0.985(-0.015,0.912-1.065)$ & $0.924(-0.079,0.845-1.010)$ & $0.911(-0.094,0.842-0.985) *$ \\
\hline
\end{tabular}

${ }^{*} p<0.05 .95 \%$ C.I, 95\% confidence interval.

\section{Cortisol and neuropeptide levels according to job}

strain. The cortisol and neuropeptide hormone levels are presented in Table 3 . The mean cortisol concentration of the total subjects was $287.7 \pm 93.1 \mathrm{nmol} / \mathrm{L}$, and concentrations of neuropeptide hormones including adiponectin, BDNF, leptin, and total ghrelin were $3.63 \pm 3.31 \mathrm{ng} / \mathrm{mL}, 21.1 \pm 7.3$ $\mathrm{pg} / \mathrm{mL}, 4.87 \pm 3.67 \mathrm{ng} / \mathrm{mL}$, and $12.7 \pm 2.6 \mathrm{pg} / \mathrm{mL}$, respectively. Despite the lack of a significant difference in measurement values of those parameters depending on job strain group, the mean BDNF concentration (19.5 $\pm 6.6 \mathrm{pg} /$ $\mathrm{mL}$ ) of the high strain group was lower than those of other groups $(\mathrm{F}=2.171, \mathrm{p}=0.091)$.

Correlation between job strain, food intake habit, and cortisol and neuropeptide levels. To examine the correlation between job stress and neuropeptide hormones, factors including age, smoking status, and alcohol drinking habit were adjusted, and then multiple logistic regression analysis was performed with neuropeptide hormones as the dependent variable and job strain, cortisol, and food intake score as independent variables. The results are presented in Table 4. Job strain was significantly correlated with adiponectin $(\mathrm{OR}, 1.220 ; \beta$ value $=0.199 ; 95 \% \mathrm{CI}, 1.002 \sim$ $1.498, p<0.05)$ and $\mathrm{BDNF}(\mathrm{OR}, 0.793 ; \beta$ value $=-0.232$; 95\% CI, $0.646 \sim 0.974 ; p<0.05)$, while food intake score was significantly correlated with ghrelin (OR, 0.911; $\beta$ value $=-0.094 ; 95 \% \mathrm{CI}, 0.842 \sim 0.985 ; p<0.05)$.

\section{DISCUSSION}

To determine the mechanisms of food intake behavior and disorders, a number of researchers have studied the neurotransmitters, neuromodulators, neuropeptides, and peripheral peptides that are involved in dietary control at the molecular level as well as energy homeostasis regulation (19).

The present study investigated the effects of neuropeptides such as adiponectin, BDNF, leptin, and ghrelin on job stress-induced changes in food intake behavior. Of the serum biochemical factors, only fasting glucose concentration was significantly lower in the high strain group, whereas the other parameters showed no significant change among job strain groups. Despite a lack of statistical significance, the BDNF concentration was lower in the high strain group $(\mathrm{F}=2.171, \mathrm{p}=0.091)$, adiponectin and BDNF were correlated with job strain, and ghrelin was correlated with food intake behavior. According to recent studies, adiponectin, BDNF, leptin, and ghrelin played modulator roles for stress-induced food intake behavior and the occurrence of eating disorders $(9,19,20)$. Jaremka et al. $(21)$ reported that females with high interpersonal tension levels had higher ghrelin and lower leptin levels and ingested greater amounts of foods with high calories, high fat, and high cholesterol as well as high amounts of sodium and sugar, which suggested that high stress is correlated with increases in body weight and the induction of obesity. Through a meta-analysis, Wardle et al. (22) reported that people with high stress had a higher proportion of body fat than people with low stress. One study using tilapia (Oreochromis mossambicus) reported that acute stress suppressed food intake and ghrelin mRNA expression in the stomach, showing that a stressrelated suppression of food intake was correlated with ghrelin signaling (23). Marcedo et al. (24) reported in an animal study of rats that stress increased adrenal gland weight and reduced hippocampal BDNF concentration, which led to increased hypercaloric intake and the induc- 
tion of obesity. In addition, leptin and ghrelin are closely related not only with stress but also with life habits, particularly smoking. It has been reported that, while smoking increased leptin concentration and reduced ghrelin concentration, leading to reduced body weight, smoking cessation increased body weight by inducing the reversal of leptin and ghrelin concentrations and causing obesity (25). The present study showed that the high strain group had a significantly lower mean fasting glucose concentration than the other strain groups, while the other serum biochemistry and anthropometric parameter values did not differ significantly between the job strain groups (Table 2). These results suggest that despite the lack of a statistically significant difference, food intake decreased in the high strain group (Table 1) by reducing BDNF concentrations and increasing ghrelin concentrations (Table 3), which led to reduced fasting glucose concentration. The HPA axis, a major neuroendocrine system, is involved not only in the adaptive response to stress but also in various responses of the body including the digestive system, immune system, emotional response, energy storage, and expenditure. Since neuropeptides are correlated with energy storage and expenditure, they are considered to play an important role in HPA axis function (12). Neuropeptides are known to be involved not only in food craving and energy balance regulation but also in emotional responses like depression and mood status $(11,12)$. Therefore, neuropeptides are highly important factors in the maintenance of the body's bionetwork (26-28). Researchers have recently studied the correlation between stress and food intake behavior as well as emotional status and neuropeptides and found that stress promoted ghrelin production (29), whereas sleep deprivation increased food consumption as an emotional response (30). Tomiyama et al. (31) reported that leptin concentration increases reduced the intake of comfort food during periods of high stress and that neuropeptides became sweet and mediated the regulation of fatty foods consumption $(32,33)$.

To examine the correlation between stress level and neuropeptides, the present study first adjusted for factors such as age, smoking, and drinking behavior and then performed multiple logistic regression analysis with adiponectin, BDNF, leptin, and ghrelin as dependent variables and job strain, cortisol, and food intake score as independent variables. Our results showed that adiponectin and BDNF were significantly correlated with job strain and that ghrelin was significantly correlated with food intake score. These results suggest that neuropeptides play a modulator role in job stress-induced changes in food intake behavior of manufacturing workers. However, while stress level was correlated with adiponectin and BDNF, ghrelin was correlated with food intake score, which may implicate that the modulator role of neuropeptides in food intake behavior may vary. In other words, we determined that adiponectin and BDNF correlated with stress level could be related with the food intake regulation system and that ghrelin could be related with emotional response, although our results require verification. Thus, it remains to be studied whether stress-induced changes in food intake behavior occur either through food intake regulation induced by neuropeptide hormone changes at the physiological level or through appetite changes induced by emotional responses to stress.

\section{ACKNOWLEDGMENTS}

This study was supported by the intramural research fund of the Occupational Safety and Health Research Institute (OSHRI).

\section{REFERENCES}

1. World Health Organization. (2012) Depression is a common illness and people suffering from depression need support and treatment. Available from: http://www.who.int/mediacentre/ news/notes/2012/mental_health_day_20121009/en/.

2. Keil, R.M. (2004) Coping and stress: a conceptual analysis. $J$. Adv. Nurs., 45, 659-665.

3. Fryer, S., Waller, G. and Kroese, B.S. (1997) Stress, coping, and disturbed eating attitudes in teenage girls. Int. J. Eating Disord., 22, 427-436.

4. Dallman, M.F. (2010) Stress-induced obesity and the emotional nervous system. Trends Endocrinol. Metab., 21, 159165.

5. Bomhof-Roordink, H., Seldenrijk, A., van Hout, H.P., van Marwijk, H.W., Diamant, M. and Penninx, B.W. (2015) Association between life stress and subclinical cardiovascular disease are partly mediated by depressive and anxiety symptoms. J. Psychosom. Res., 78, 332-339.

6. Woods, S.C. and Seeley, R.J. (2005) Hormonal mediation of energy homeostasis in obesity, diabetes and related disorders. Drug Discovery Today Dis. Mech., 2, 321-326.

7. Moons, W.G., Eisenberger, N.I. and Taylor, S.E. (2010) Anger and fear response to stress have different biological profiles. Brain Behav. Immu., 24, 215-219.

8. Spoor, S.T., Bekker, M.H., Van Strien, T. and van Heck, G.L. (2007) Relations between negative affect, coping, and emotional eating. Appetite, 48, 368-376.

9. Lebrun, B., Bariohay, B., Moyse, E. and Jean, A. (2006) Brain-derived neurotrophic factor (BDNF) and food intake regulation: a minireview. Auton. Neurosci., 126-127, 30-38.

10. Nour, H.A., El Sawaf, A.L., Elewa, S.M. and El Sayed, Y. (2014) Strength and independence of associations between ghrelin, leptin, adiponectin and insulin in stimulating basic functions to energy metabolism. Alexandria J. Med., 50, 4959.

11. Spencer, S.J., Emmerzaal, T.L., Kozicz, T. and Andrews, Z.B. (2015) Ghrelin's role in the hypothalamic-pituitary-adrenal axis stress response: Implications for mood disorders. Biol. Psychiatry, 78, 19-27.

12. Stieg, M.R., Sievers, C., Farr, O., Stalla, G.K. and Mantzoros, C.S. (2015) Leptin: A hormone linking activation of neuroendocrine axes with neuropathology. Psychoneuroendocrinol- 
ogy, 51, 47-57.

13. Appelhans, B.M., Pagoto, S.L., Peters, E.N. and Spring, B.J. (2010) HPA axis response to stress predicts short-term snack intake in obese women. Appetite, 54, 217-220.

14. Fernández-Real, J.M., López-Bermejo, A., Casamitjana, R. and Ricart, W. (2003) Nevel interactions of adiponectin with the endocrine system and inflammatory parameters. J. Clin. Endocrinol. Metab., 88, 2714-2718.

15. Issa, G., Wilson, C., Terry, A.V. Jr. and Pillai, A. (2010) An inverse relationship between cortisol and BDNF levels in schizophrenia: data from human postmortem and animal studies. Neurobiol. Dis., 39, 327-333.

16. Raspopow, K., Abizaid, A., Matheson, K. and Anisman, H. (2014) Anticipation of a psychosocial stressor differentially influences ghrelin, cortisol and food intake among emotional and non-emotional eaters. Appetite, 74, 35-43.

17. Karasek, R. (1996) Job content questionnare and user's guide. University of Massachusetts at Lowell.

18. Son, M.S. and Kim, M.J. (2001) The effects of nutrition education program for various chronic disease in elderly visiting public health center. Korean J. Community Nutr., 6, 668-677.

19. Monteleone, P. and Maj, M. (2013) Dysfunctions of leptin, ghrelin, BDNF and endocannabinoids in eating disorders: beyond the homeostatic control of food intake. Psychoneuoendocrinology, 38, 313-330.

20. Fernandez-Real, J.M., Pugeat, M., López-Bermejo, A., Bornet, H. and Ricart, W. (2005) Corticosteroid-binding globulin affects the relationship between circulating adiponectin and cortisol in men and women. Metab. Clin. Exp., 54, 584-589.

21. Jaremka, L.M., Belury, M.A., Andridge, R.R., Malarkey, W.B., Glaser, R., Christian, L., Emery, C.F. and Kiecolt-Glaser, J.K. (2014) Interpersonal stressors predict ghrelin and leptin levels in women. Psychoneuoendocrinology, 48, 178188.

22. Wardle, J., Chida, Y., Gibson, E.L., Whitaker, K.L. and Steptoe, A. (2011) Stress and adiposity: a meta-analysis of longitudinal studies. Obesity, 19, 771-778.

23. Upton, K.R. and Riley, L.G. (2013) Acute stress inhibits food intake and alters gkrelin signaling in the brain of tilapia (Oreochromis mossabbicus). Domest. Anim. Endocrinol., 44, 157-
164.

24. Marcedo, I.C., Rozisky, J.R., Oliveira, C., Oliveria, C.M., Laste, G., Nonose, Y., Santos, V.S., Marques, P.R., Ribeiro, M.F., Caumo, W. and Torres, I.L. (2015) Chronic stress associated with hypercaloric diet changes the hippocampal BDNF levels in male Wistar rats. Neuropeptides, 51, 75-81.

25. Lee, H., Joe, K.H., Kim, W., Park, J., Lee, D.H., Sung, K.W. and Kim, D.J. (2006) Increased leptin and decreased ghrelin level after smoking cessation. Neurosci. Lett., 409, 47-51.

26. Onen Sertoz, O., Tolga Binbay, I., Koylu, E., Noyan, A., Yildirim, E. and Elbi Mete, H. (2008) The role of BDNF and HPA axis in the neurobiology of burnout syndrome. Prog. Neuro Psychopharmacol. Biol. Psychiatry, 32, 1459-1465.

27. Şahin, T.D., Karson, A., Balci, F., Yazir, Y., Bayramgürler, D. and Utkan, T. (2015) TNF-alpha inhibition prevent cognitive decline and maintains hippocampal BDNF levels in the unpredictable chronic mild stress rat model of depression. Behav. Brain Res., 292, 233-240.

28. Yang, S., Meredith, P. and Khan, A. (2015) Stress and burnout among healthcare professional working in a mental health setting in Singapore. Asian J. Psychiatry, 15, 15-20.

29. Ochi, M., Tominaga, K., Tanaka, F., Tanigawa, T., Shiba, M., Watanabe, T., Fujiwara, Y., Oshitani, N., Higuchi, K. and Arakawa, T. (2008) Effect of chronic stress on gastric emptying and plasma ghrelin levels in rats. Life Sci., 82, 862-868.

30. Knutson, K.L., Spiegel, K., Penev, P. and Van Cauter, E. (2007) The metabolic consequences of sleep deprivation. Sleep Med. Rev., 11, 163-178.

31. Tomiyama, A.J., Schamarek, I., Lustig, R.H., Krischbaum, C., Puterman, E., Havel, P.J. and Epel, E.S. (2012) Leptin concentrations in response to acute stress predict subsequent intake of comfort foods. Physiol. Behav., 107, 34-39.

32. Oliver, G., Wardle, J. and Gibson, E.L. (2000) Stress and food choice: a laboratory study. Psychosom. Med., 62, 853-865.

33. Dalman, M.F., Pecoraro, N., Akana, S.F., La Fleur, S.E., Gomez, F., Houshyar, H., Bell, M.E., Bhatnagar, S., Laugero, J.D. and Manalo, S. (2003) Chronic stress and obesity: a new view of "comfort food". Proc. Natl. Acad. Sci. U.S.A., 100, 11696-11701. 